\title{
TIPOLOGÍA DE ESTADOS DE COSAS Y ASIGNACIÓN DE FUNCIONES SEMÁNTICAS EN LA TEORÍA DE LA GRAMÁTICA FUNCIONAL: APROXIMACIONES CRÍTICAS $^{12}$
}

\author{
Pilar Guerrero Medina, Universidad de Córdoba \\ Email: ff1gumep@uco.es
}

\begin{abstract}
This paper is concerned with one specific area of S.C. Dik's theory of Functional Grammar (FG) which has received a great deal of attention within the FG movement: the classification of States of Affairs and semantic functions. I will first focus on Dik's $(1978,1989,1997)$ proposals for a typology of SoAs, then presenting other alternative approaches by authors such as Rijksbaron (1989) and Goossens (1990), who suggested some interesting refinements of the 1978 and 1989 versions. Finally, the assignment of semantic and syntactic functions in FG will be briefly discussed, including some more recent advances and critical evaluations of Dik's work.

Keywords: States of Affairs (SoAs), semantic functions, syntactic functions, Functional Grammar

Title in English: Typology of States of Affairs and semantic function assignment in the theory of Functional Grammar: critical approaches

Resumen: Este trabajo pretende profundizar en un área de la teoría de la Gramática Funcional (GF) de S.C. Dik que ha recibido especial atención dentro del modelo: la clasificación de los estados de cosas y la asignación de funciones semánticas. En primer lugar, se analizan las propuestas de $\operatorname{Dik}(1978,1989,1997)$ presentándose a continuación las aportaciones de otros autores, como Rijksbaron (1989) y Goossens (1990), que introdujeron interesantes modificaciones respecto a las versiones de 1978 y 1989. Finalmente, se abordará brevemente el tema de la asignación de funciones semánticas y sintácticas en la GF, incluyendo algunas de las aportaciones y valoraciones críticas más recientes.

Palabras clave: Estados de cosas (EdCs), funciones semánticas, funciones sintácticas, Gramática Funcional
\end{abstract}

\footnotetext{
Date of reception: 20 June 2011

Date of acceptance: 19 July 2011

2 El presente trabajo, realizado el marco del proyecto FFI2008-04448/FILO, es una versión revisada y ampliada de la conferencia "Tipología de EdCs y asignación de funciones semánticas en la teoría de la GF (1989/1997)", pronunciada en el marco del Seminario Internacional de Investigación Tradición y renovación en la Gramática Funcional, organizado por el profesor Javier Martín Arista en la Universidad de La Rioja (mayo, 2008). Agradezco las observaciones de un evaluador anónimo.
} 


\section{INTRODUCCIÓN}

Desde que S.C. Dik publicara su Gramática Funcional (Functional Grammar) en 1978, la tipología de los estados de cosas (EdCs) y la asignación de funciones semánticas han sido objeto de una especial atención dentro del modelo de la Gramática Funcional (en adelante, GF). Entre los primeros trabajos que abordaron el tema desde una perspectiva crítica podemos citar los siguientes: Mackenzie (1981), De Groot (1983), Vester (1983) y Rijksbaron (1989). Tras la publicación de la Teoría de la Gramática Funcional de 1989, que sería posteriormente revisada en 1997 por Kees Hengeveld, la propuesta de una nueva tipología de EdCs, en la que ya se incorporaban algunas de las modificaciones sugeridas por autores como Vester (1983) o De Groot $(1983,1985),{ }^{3}$ siguió siendo objeto de discusión, y de nuevo surgieron voces críticas dentro del modelo. Así, en 1990 Goossens propone una revisión de la tipología de Dik, inspirándose en la clasificación de tipos de Procesos de la Gramática Sistémica Funcional, y en 1991 Siewierska sugiere modificaciones interesantes que afectan tanto a la definición de los mismos parámetros clasificatorios (control, telicidad y dinamismo) como a la de las funciones semánticas asociadas a cada uno de los tipos de EdCs propuestos por el lingüista holandés. ${ }^{4}$

El trabajo está organizado como sigue: la sección 2 presenta primero el "estado de la cuestión" en la formulación clásica del modelo, trazándose la evolución desde la primera exposición de la teoría en 1978 hasta 1997. En la sección 2.1 se resumen las aportaciones críticas más relevantes que se han realizado dentro del modelo entre 1989 y 1997 . A continuación se aborda la asignación de funciones semánticas y sintácticas en la teoría (secciones 3.1 y 3.2), y se ofrecen también algunas de las revisiones críticas más recientes en este área de la G. F. (sección 3.3). La sección 4 presenta algunos comentarios finales, a modo de conclusión.

\section{LOS ESTADOS DE COSAS EN LA GRAMÁTICA FUNCIONAL}

En la GF, un modelo de orientación ascendente que parte desde las unidades léxicas, la combinación de predicados y términos da como resultado una predicación nuclear. ${ }^{6}$ Los predicados son expresiones que designan propiedades o relaciones, mientras que los

\footnotetext{
Dik (1997: 105-106; n 1) reconoce su deuda con estos dos autores, citando también los trabajos de Vendler (1967), Comrie (1976) y Dowty (1979), entre otros, como fuente de inspiración fuera del modelo para elaborar su propia tipología de EdCs. El paralelismo entre ésta y las clasificaciones de Vendler (págs. 97 ss.) y Dowty (p. 54) es particularmente evidente.

4 La mayoría de los autores citados aplican la tipología de la GF, postulada como una clasificación de validez universal, a una lengua específica. Tanto Rijksbaron (1989) como Goossens (1990) utilizan el inglés como lengua de referencia. Vester (1983), en cambio, aplica la tipología de Dik (presentada en la versión de 1978) al latín. De Groot (1985), por su parte, utiliza ejemplos del inglés y del húngaro para justificar sus aserciones.

5 En adelante, para la traducción de la terminología técnica me basaré fundamentalmente en la propuesta por García Velasco (2003) en su magnífica presentación actualizada de la teoría de la GF, que el propio autor (p. 11) define como "una introducción afectuosamente crítica" al modelo. También me ha resultado de utilidad el glosario de términos incluido por Martín Mingorance y Serrano Valverde en su traducción al español de la presentación original de la teoría (cfr. Dik 1981/1978).

6 En las versiones de 1989 y 1997, Dik postula la estructura jerárquica de la cláusula, incorporando la propuesta de Hengeveld (1989). La formación de una estructura subyacente totalmente especificada es el resultado
} 
términos hacen referencia a entidades. Cada predicado básico aparece formulado en el lexicón como un marco predicativo en el que se expresan las propiedades básicas que lo definen. En (1) se ofrece un ejemplo de marco predicativo (Dik 1997: 59):?

$$
\text { (1) give }[\mathrm{V}]\left(\mathrm{x}_{1}<\operatorname{anim}>\left(\mathrm{x}_{1}\right)\right)_{\mathrm{Ag}}\left(\mathrm{x}_{2}\right)_{\mathrm{Go}}\left(\mathrm{x}_{3}:<\operatorname{anim}>\left(\mathrm{x}_{3}\right)\right)_{\mathrm{Rec}}
$$

Una predicación nuclear designa un conjunto de EdCs, cada uno de los cuales viene definido por la propiedad o relación específica designada por el predicado (Dik 1997: 105). ${ }^{8}$ El término "estado de cosas" ("state of affairs") es empleado en la teoría de un modo amplio para designar "la concepción de algo que puede ser el caso en algún mundo" (Dik 1989: 89; 1997: 105).

Dik (1997: 124) considera que cada EdC responde a una visión o codificación de la realidad y que no constituye parte de ésta. ${ }^{9}$ Los ejemplos en (2), muchos inaceptables en inglés, corresponden a posibles conceptualizaciones distintas de una misma realidad en distintas lenguas y por tanto a distintos tipos de EdCs: ${ }^{10}$

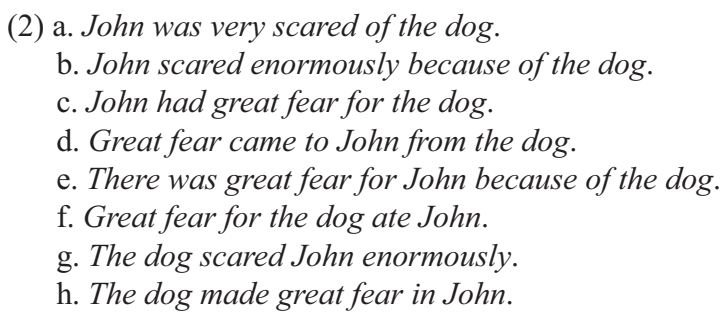

Es importante señalar que las distinciones realizadas en la tipología de EdCs de la GF no están únicamente determinadas por las propiedades del predicado, sino que resultan de la interacción entre las propiedades léxicas del predicado y los términos a los que éste se aplica. ${ }^{11}$ En palabras de Dik (1997: 106): "the SoA type is then a compositional function of the semantic properties of both predicates and terms" (énfasis mío). El autor (ibid) utiliza

\footnotetext{
de un proceso gradual. Cada estructura se va insertando en un estadio superior hasta proyectarse finalmente en la expresión lingüística (cfr. Dik 1997: 50).

7 En (1) se especifica que give es un predicado verbal, que requiere tres posiciones argumentales, indicadas por las variables x. Los argumentos desempeñan las funciones semánticas Agente ("Ag(ent)"), Meta ("Go(al)") y Receptor ("Rec(ipient)"). El predicado establece la restricción de selección < animado> sobre la primera y tercera posición argumental.

$8 \quad$ Cfr. Dik (1978: 32; 1989: 89).

9 En otros modelos teóricos, el término "state of affairs" es utilizado para designar una realidad, y no la conceptualización de la misma. Así, en el marco de la Gramática del Papel y la Referencia (Role and Reference Grammar) el término refiere a "fenómenos reales" (Van Valin y LaPolla 1997: 83). Por otra parte, en la más reciente Gramática Funcional del Discurso (Functional Discourse Grammar), un modelo que supone una reorganización de la estructura de la GF, los estados de cosas son también definidos como "entidades" reales: "States-of-affairs are entities that can be located in relative time and can be evaluated in terms of their reality status" (Hengeveld y Mackenzie 2008: 116).

10 Como acertadamente afirma García Velasco (2003: 118), resulta importante señalar la coincidencia de planteamientos existente en este sentido entre la GF y la orientación cognitivo-funcional.

11 Esta idea está también presente en De Groot (1983: 80; n 1) y Rijksbaron (1989: 33). Del mismo modo, autores como Quirk et al., que clasifican los significados verbales en once categorías o "situation types" equivalentes a
} 
el término Aktionsart o Modo de Acción ("Mode of Action") como sinónimo de Tipo de $E d C$ ("Type of SoA"), para referirse a las distinciones aspectuales que conciernen a la semántica interna de la predicación. El término Aspecto ("Aspect") se reserva para designar las distinciones expresadas por medios gramaticales (p.ej., las oposiciones perfectivo/ imperfectivo y progresivo/no progresivo). ${ }^{12}$

Como muestra la Tabla 1, en el modelo de 1978 se distinguían únicamente dos parámetros diferenciadores: Dinamismo ("Dynamism") y Control ("Control”). La interacción entre estos dos factores daba lugar a cuatro tipos básicos de EdCs: State ("Estado") = EdC no dinámico y no controlado; Proceso ("Process") = EdC dinámico y no controlado; Posición ("Position") = EdC no dinámico y controlado; Acción (“Action”) = EdC dinámico y controlado.

\begin{tabular}{|l|c|c|}
\hline & [+dinámico $]$ & [-dinámico] \\
\hline$[+$ control & Acción & Posición \\
\hline$[$-control $]$ & Proceso & Estado \\
\hline
\end{tabular}

Tabla 1. Tipología de EdCs en Dik (1978: 33).

En las versiones de la GF de 1989 y 1997 los EdCs son clasificados de acuerdo a los parámetros presentados en (3):

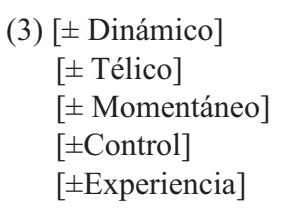

Los tres primeros caracterizan la estructura temporal interna del EdC, mientras que los dos últimos definen la función semántica de los argumentos en la predicación.

El tratamiento de los EdCs y funciones semánticas no ha sufrido modificaciones sustanciales entre 1989, fecha de la primera edición de la Teoría de la Gramática Funcional, y 1997, año en el que se publicó la edición revisada por Kees Hengeveld. En adelante, por tanto, las referencias corresponderán en su mayoría a la versión de 1997.

A continuación definiré cada uno de estos parámetros, incluyendo los ejemplos en inglés que Dik presenta para ilustrar cada uno de los tipos de EdCs resultantes de la aplicación de los mismos. ${ }^{13}$

\footnotetext{
los EdCs de la GF, afirman: "It is important to note, also, that verb meanings can be separated only artificially (...) from their complementations" (1985: 200).

12 El término Aktionsart denota, pues, el equivalente léxico de la categoría gramatical Aspecto (cfr. Siewierska 1991: 231; n 2). Esta precisión es relevante ya que, como apunta Comrie (1976: 6-7), en la literatura existe una confusión terminológica en el área de las distinciones aspectuales, donde el término "Aspecto" se utiliza indistintamente para designar las oposiciones que son gramaticalizadas o lexicalizadas por las lenguas y aquéllas que no lo son.

13 Cabe señalar que, aunque la tipología de los EdCs en la GF se postula como una clasificación de validez universal, se utilizan exclusivamente ejemplos del inglés para ilustrar la aplicación de los distintos parámetros (Dik 1997; capítulo 5).
}

Odisea, ${ }^{\circ} 12$, ISSN 1578-3820, 2011, 331-349 
El primero de estos es el parámetro [ \pm dinámico], definido en términos de la noción “cambio" (cfr. Dik 1997: 107). Un EdC [-din] es aquél que no implica ningún cambio, i.e. aquél en el que las entidades participantes permanecen inalterables en todos los puntos del intervalo de tiempo durante el que tiene vigencia el EdC. Los EdCs [+din], por el contrario, necesariamente implican algún tipo de cambio, de "dinamismo interno" (cfr. Dik 1997: 107). La aplicación de este parámetro establece una distinción entre Situaciones ("Situations"), o EdCs [-din], y Eventos ("Events") o EdCs [+din], ilustrados con los ejemplos en (4):
(4) a. The substance was red. [-din]
b. The clock was ticking. [+din]

El segundo de los parámetros enumerados en (2) establece una distinción entre EdCs [+télicos] y [-télicos]. Un EdC es aquél que se realiza completamente sólo si alcanza el punto final al que estaba dirigido (cfr. Dik 1997: 108). La aplicación de este parámetro subclasifica los EdCs dinámicos en cuatro categorías: Realización (“Accomplishment”), Cambio ("Change"), Actividad ("Activity") y Dinamismo ("Dynamism"). Las dos primeras corresponden a EdCs télicos; las dos segundas a EdCs no télicos.

La telicidad puede estar determinada por la naturaleza del segundo argumento, como muestran las oraciones en (5), por la presencia de un satélite direccional, como en (6), o por las características del primer argumento, como se ilustra en (7), ejemplos tomados de $\operatorname{Dik}(1997: 108-109):^{14}$
(5) a. John was painting.
[-tel]
b. John was painting a portrait.
$[+$ tel $]$
c. John was painting portraits.
[-tel]
(6) a. John walked in the park.
b. John walked to the station.
[-tel]
$[+$ tel $]$
(7) a. Demonstrators were passing the station. [-tel]
b. The demonstrators were passing the station. [+tel]

Dentro de la categoría de Eventos [+télicos], Dik distingue entre EdCs [+momentáneos] y EdCs [-momentáneos]. Los primeros carecen de duración: su inicio coincide con su punto final, ocupando únicamente un punto en el tiempo. Los Eventos [-mom], por el contrario, ocupan un intervalo de tiempo, con un inicio y término claramente diferenciados. La incompatibilidad con verbos aspectuales que designen el comienzo, continuación o final del evento revela el carácter [+mom] del evento, como es el caso en $(8 b)$ :
(8) a. John started / continued / finished painting the portrait. b. *John started / continued / finished reaching the summit.
[-mom]
$[+\mathrm{mom}]$

14 Dik (1997: 109-110) establece cuatro pruebas sintácticas de carácter aspectual para determinar la telicidad de un EdC: (i) incompatibilidad con el satélite de duración for an hour; (ii) posibilidad de insertar la predicación télica en expresiones del tipo "It took X three hours to ..."; (iii) diferentes interpretaciones derivadas de la combinación con almost; (iv) implicaciones semánticas derivadas de la combinación con el aspecto progresivo. 
El parámetro [ \pm control] interactúa con los anteriores, subclasificando las Situaciones en Posiciones ("Positions") y Estados ("States"), y los Acontecimientos en Acciones (“Actions") y Procesos ("Processes"). Las Posiciones y Acciones son EdCs [+controlados]; los Estados y Procesos son EdCs [-controlados]. Un EdC es [+con] si la entidad que ocupa la primera posición argumental tiene la capacidad de determinar si ese Edc tendrá o no lugar (cfr. Dik 1997: 112). ${ }^{15}$
(9) a. John opened the door.
$[+$ con $]$
b. John mislaid the present.
$[-\operatorname{con}]$

En la versión de 1989, la interacción entre los parámetros $[ \pm$ din $],[ \pm$ con $]$ y $[ \pm$ tel $]$ daba lugar a la tipología de EdCs presentada en la Figura 4.

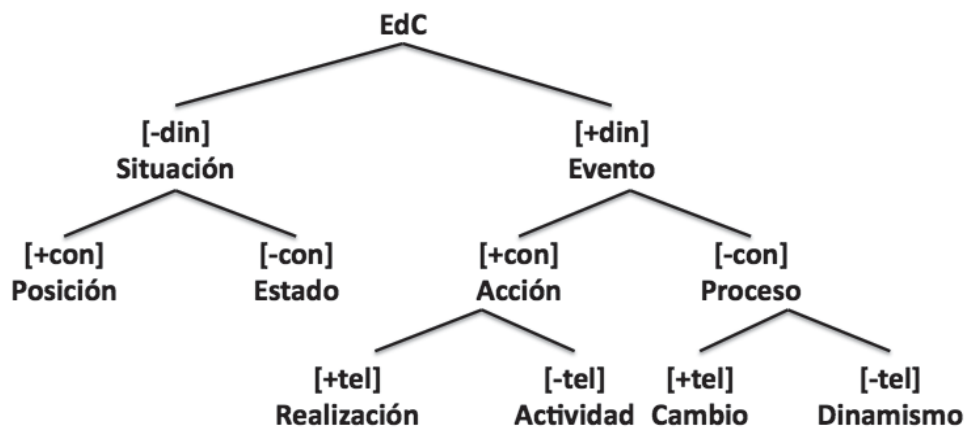

Figura 1. Tipología de EdCs en Dik (1989:98) ${ }^{16}$.

En la edición de 1997 se sustituye el diagrama arbóreo por la presentación en la Tabla 2 , en la que la relación jerárquica entre los parámetros no es tan obvia: ${ }^{17}$

\begin{tabular}{|l|c|c|}
\hline & {$[+$ control] } & {$[$-control] } \\
\hline Situación [-din] & Posición & Estado \\
\hline Evento [+din] & Acción & Proceso \\
\hline Evento [-tel] & Actividad & Dinamismo \\
\hline Evento [+tel] & Realización & Cambio \\
\hline
\end{tabular}

Tabla 2. Tipología de EdCs en Dik (1997: 114).

\footnotetext{
15 La relevancia de la distinción entre EdCs controlados y no controlados es demostrada mediante una serie de pruebas sintácticas, entre ellas la compatibilidad con adverbios como deliberately o intentionally (cfr. Dik 1997: 113-114 y Siewierska 1991: 48).

16 En (10) se presentan los términos originales para cada tipo de EdC.

17 Autores como De Groot (1983) y Siewierska (1991) habían cuestionado la validez de la relación jerárquica entre los parámetros de la tipología de Dik.
}

Odisea, ${ }^{\circ} 12$, ISSN 1578-3820, 2011, 331-349 
Los ejemplos en (10), tomados de Dik (1997: 114), ilustran cada uno de estos tipos de EdCs:

(10) Posición (Position): Estado (State):

Actividad (Activity):

Dinamismo (Dynamism):

Realización (Accomplishment):

Cambio (Change):
John kept his money in an old sock. John's money is in an old sock.

John was reading a book.

The clock was ticking.

John ran the marathon in three hours.

The apple fell from the tree.

Todos los EdCs presentados en la Tabla 2 pueden ocurrir como [+experienciales] y [-experienciales]. Una Experiencia es un EdC que sólo se obtiene por medio de las facultades mentales o sensoriales de un ser animado. Es, en definitiva, un EdC en el que un ser animado percibe, siente, quiere, concibe o, en suma, experimenta algo (cfr. Dik 1997: 115). Los ejemplos en (11) ilustran las versiones experienciales de los EdCs presentados en la Tabla 2 (Dik 1997: 115):

(11) Posición [+exp]: Estado [+exp]: Actividad [+exp]: Dinamismo [+exp]: Realización [+exp]: Cambio [+exp]:

\author{
John did not believe the story. \\ John did not know the story. \\ John was thinking about his money problems \\ John dreamed about his girl friend. \\ John conceived a clever trick. \\ John got an interesting idea.
}

Dik indica que la oposición [ \pm experiencial] no tiene un gran impacto gramatical en las diversas lenguas. De ahí que trate esta noción como una función semántica secundaria, "a 'footnote' to the other first argument functions" (1997: 119). Sin embargo, el autor señala que hay lenguas, sin embargo, en las que las predicaciones [-con] y [+exp] son expresadas de forma diferente a las correspondientes predicaciones [-exp], como se ilustra mediante la paráfrasis inglesa en (12b). El autor reconoce la necesidad de introducir la distinción [ \pm exp] para diferenciar este tipo de construcciones.
(12) a. Estado [-exp]:
b. Estado [+exp]:
John did not sleep on the ground. To John was not known the story. ( ${ }^{*}$ John did not know the story.)

\subsection{Aproximaciones críticas}

En esta sección se presentan, en primer lugar, las aportaciones críticas de Rijksbaron (1989) y Goossens (1992). Estos dos autores revisan la clasificación de EdCs postulada por Dik, aplicándola al inglés. La primera toma como punto de partida la versión de 1978, mientras la segunda está basada en la edición de 1989. Se resumirán también a continuación algunas de las observaciones y sugerencias de Siewierska (1991) en su revisión crítica de este área de la GF. 
Según Rijksbaron (1989: 10), la tipología de EdCs propuesta por Dik en 1978 parte de un tratamiento erróneo de las nociones de "dinamismo" y “cambio." El autor propone una redefinición de la noción cambio como un rasgo significativo inherente de ciertos estados de cosas, no aplicable a todos los tipos de cambio existentes en la realidad. En la nueva tipología de Rijksbaron, que presento en la Tabla 3, hay dos parámetros clasificatorios: [ \pm cambio] y [ \pm control]. Su concepción del parámetro cambio está basada en la distinción aristotélica entre kineseis y energeiai. Sólo aquellos EdCs con un objetivo final inherente y cuya realización requiera tiempo (esto es, los EdCs télicos en la tipología de Dik) implican cambio, en un sentido estricto. ${ }^{18}$

Se excluye por tanto la combinación [+din] [-tel], que caracteriza al tipo de EdC "Dinamismo" en la GF de Dik, y la "telicidad" pasa a ser el parámetro clasificatorio inicial en esta tipología.

\begin{tabular}{|c|c|c|c|c|}
\hline & kineseis [+change] & \multicolumn{3}{|c|}{ energeiai [-change] } \\
\hline & $\begin{array}{l}\text { directed towards } \\
\text { inherent endpoint }\end{array}$ & \multicolumn{2}{|c|}{ may be continued (durative) } & may not be continued \\
\hline & accomplishments & $\begin{array}{l}\text { for a limited } \\
\text { time }\end{array}$ & $\begin{array}{l}\text { (semi- } \\
\text { permanently) }\end{array}$ & $\begin{array}{l}\text { momentaneous, } \\
\text { punctual, compact }\end{array}$ \\
\hline [+control] & $\begin{array}{l}\text { draw (a circle) } \\
\text { open (a door) } \\
\text { drink (the wine) } \\
\text { repair (a bicycle }\end{array}$ & $\begin{array}{l}\text { activities } \\
\text { look (at) } \\
\text { walk (along } \\
\text { x) } \\
\text { push (a cart) }\end{array}$ & & $\begin{array}{l}\text { acts } \\
\text { seize (a burglar) } \\
\text { kill (an enemy) } \\
\text { invite (a guest) }\end{array}$ \\
\hline [-control] & $\begin{array}{l}\text { developments } \\
\text { (processes) } \\
\text { recover } \\
\text { melt } \\
\text { fall down } \\
\text { grow up }\end{array}$ & $\begin{array}{l}\text { dispositions } \\
\text { sleep } \\
\text { laugh } \\
\text { sit } \\
\text { goings-on } \\
\text { snow } \\
\text { rain }\end{array}$ & $\begin{array}{l}\text { states } \\
\text { be old } \\
\text { be a teacher } \\
\text { know (=have } \\
\text { the knowledge } \\
\text { of) } \\
\text { love }\end{array}$ & $\begin{array}{l}\text { happenings, achieve- } \\
\text { ments } \\
\text { find (a coin, a solu- } \\
\text { tion) } \\
\text { notice (a painting) } \\
\text { know (the answer) } \\
\text { achievements } \\
\text { reach (the summit, } \\
\text { a verdict) } \\
\text { arrive }\end{array}$ \\
\hline
\end{tabular}

Tabla 3. Tipología de EdCs en Rijksbaron (1989: 15).

La aportación de Goossens (1990) respecto a la clasificación propuesta por Dik en 1989 (véase la Figura 1), está inspirada en la clasificación de Procesos postulada por Halliday

\footnotetext{
18 Basándome en la definición de la noción "cambio" propuesta por Rijksbaron (1989), en Guerrero Medina (1998) presenté una tipología alternativa con dos parámetros clasificatorios: $[ \pm$ control] y [ \pm cambio], donde el primero se postulaba como el rasgo clasificatorio inicial.
} 
(1985) dentro del marco de la Gramática Sistémica Funcional (GSF). En la GSF los Procesos Mentales constituyen una categoría independiente, y Goossens (1990-175-177) se plantea la posibilidad de reconocer también las Experiencias como un subtipo adicional de la categoría Situaciones, y que se distinguiría de las Posiciones y Estados por la presencia del rasgo [+Cognizant], como se muestra en (13):

(13) Situaciones:

Posiciones: [+con], [-din]

Estados: [-con], [-din]

Experiencias: [-con], [+cog], [-din]

Predicaciones como las presentadas en (14) ilustrarían este último subtipo de Situaciones, donde el primer argumento sería propiamente un Experimentante.

(14) a. John (Exp) did not know the story.

b. Mary (Exp) liked the gift.

c. I (Exp) saw the sea.

Goossens (1990: 186) considera que, al partir la GF de un ideal de adecuación tipológica y pretender por tanto llegar a una clasificación de EdCs de validez universal, corre el riesgo de no funcionar cuando se aplica a una lengua específica, como sería el caso del inglés. Uno de los argumentos en los que el autor (1990: 173) se basa para hablar de Experiencias es el hecho de que el presente simple (y no el progresivo) sea el tiempo verbal no marcado para este tipo de EdCs mentales. Así pues, podemos deducir que la propuesta de Goossens, es únicamente aplicable al inglés, y no es por tanto fácilmente exportable a otras lenguas.

Las observaciones críticas de Siewierska (1991) se centran en el tratamiento de los parámetros "control", "telicidad" y "dinamismo" en la GF. ${ }^{19}$ En relación al primero, la autora (1991: 48) se muestra partidaria de diferenciar entre las nociones de "control" e "intencionalidad" (o "volición"), que no se definen de forma independiente en la GF, donde el Agente, definido de forma muy restrictiva, ha de ser forzosamente una entidad animada, que actúe de forma intencional. Como afirma la autora (1991: 69), esta visión es contraria a la mayoría de las caracterizaciones de la noción agentividad en otros marcos teóricos. ${ }^{20}$

Siewierska (1991: 51-52) también aborda algunos de los problemas que plantea la definición y aplicación del parámetro "telicidad" en la tipología de Dik. En primer lugar, como señala autora, el tratamiento de los EdCs [+momentáneos] como télicos es problemático: un EdC que carezca de duración no puede ser caracterizado como télico,

\footnotetext{
19 Véase también Butler (2003: 409-412), donde se exponen los principales problemas que la tipología de los EdCs de la GF plantea en relación a estos parámetros y a la naturaleza jerárquica de los rasgos que la definen. El autor (2003: 412 ss.) ofrece a continuación una interesante comparación crítica entre la tipología de EdCs en el modelo dikkeano y las clasificaciones propuestas en otros dos modelos funcionalistas: la Gramática del Papel y la Referencia y la Gramática Sistémica Funcional.

20 En la teoría de la GF no se especifica si la presencia de un modificador adverbial como "accidentally" cancela o no el parámetro "control”. Según Siewierska (1991: 49), cabría esperar que sí, siendo coherentes con la tipología de funciones semánticas que Dik postula, y al primer argumento de un cláusula como I accidentally tore the cover se le asignaría entonces la función Fuerza, y no la de Agente.
} 
ya que la realización de un EdC [+télico] implica necesariamente un período de tiempo limitado.

En cuanto al parámetro "dinamismo", según Siewierska (1991: 53), no existen argumentos lingüísticos claros que apoyen la distinción realizada por Dik entre Situaciones y Eventos. El único factor sintáctico mencionado para diferenciar estos dos tipos de EdCs es la incompatibilidad de los primeros con los satélites de velocidad de nivel 1, como se ilustra en (15), y éste no parece un criterio lo suficientemente fundamentado, especialmente si tenemos en cuenta que los EdCs de la tipología de Dik se definen en el nivel de la predicación nuclear, al que no pertenecen los satélites.

$$
\begin{array}{ll}
\text { (15) a. The substance was red }(* \text { quickly). } & {[-\mathrm{din}]} \\
\text { b. The clock was ticking quickly. } & {[+\mathrm{din}]}
\end{array}
$$

Por otra parte, el hecho de que sólo los EdCs dinámicos sean clasificados como [ \pm télicos] es otra deficiencia del modelo de Dik, ya que las Situaciones (EdCs no dinámicos, que carecen de un punto final inherente y no implican cambio) deberían ser clasificados como atélicos (cfr. Siewierska 1991: 54).

Dik (1997: 106-107) afirma que las distinciones postuladas en su tipología afectan únicamente a la semántica interna de la predicación nuclear. Sin embargo, su clasificación no es del todo coherente con este planteamiento inicial, ya que hay casos en que es la presencia de un satélite la que determina el tipo de EdC. En este sentido, ejemplos como los presentados en (6) son problemáticos, ya que en John walked to the station es el satélite de dirección "to the station" el que define esta predicación como Realización (EdC [+télico]) y no como Actividad (EdC [-télico]). Como afirma Siewierska (1991: 56): “If SoAs are defined on nuclear predications, we would not expect satellites, which do not belong to the nuclear predication, to affect the nature of the SoA". ${ }^{21}$

Como sostengo en un trabajo anterior (Guerrero Medina 2001), sería conveniente redefinir el parámetro "telicidad" en la teoría de la GF, distinguiendo claramente entre las nociones de "aspectualidad léxica" y "aspectualidad gramatical", ya que algunas de las distinciones establecidas en la tipología de EdCs del modelo están basadas en factores gramaticales, ajenos a la semántica interna de la predicación. Así, por ejemplo, Dik (1997: 114) utiliza una expresión en aspecto progresivo como John was reading a book para ilustrar la categoría Actividad, cuando en realidad esta construcción correspondería, en mi opinión, a un tipo de $\mathrm{EdC}$ [+télico], con un objetivo final inherente, pero presentado gramaticalmente como "no demarcado" (unbounded) al no haber alcanzado un limite temporal (Depraetere 1995: 2-3).

\footnotetext{
21 Sostiene Soto (2008: 203) que una manera de resolver este problema es que "el contexto lingüístico y extralingüístico tenga la facultad de alterar las especificaciones del EdC", proponiendo que la tipología de EdCs de Dik funcione prototípicamente, de modo que sus propiedades puedan ser canceladas o sustituidas. Como afirma el autor, este enfoque tendría efectivamente cabida en un modelo de "orientación descendente" (top-down organization) como la Gramática Funcional del Discurso, que parte de la intención comunicativa del hablante, y cuyo objetivo es la descripción de unidades discursivas y no de cláusulas aisladas (cfr. Hengeveld y Mackenzie 2008: 1-3).
}

Odisea, $n^{\circ} 12$, ISSN 1578-3820, 2011, 331-349 


\section{ASIGNACIÓN DE FUNCIONES SEMÁNTICAS Y SINTÁCTICAS EN LA GF}

La GF especifica las relaciones funcionales en tres niveles diferentes: semántico, sintáctico y pragmático. En esta sección me centraré en los dos primeros niveles, íntimamente conectados en la teoría.

\subsection{Funciones semánticas}

En la GF hay una clara correspondencia entre las funciones semánticas y los tipos de EdCs que se distinguen en el modelo, ya que las funciones semánticas especifican los roles que desempeñan las entidades en el EdC designado por la predicación. ${ }^{22}$ Así pues, la función semántica del primer argumento reflejará, en gran medida, la tipología de EdCs en la Figura 1 y Tabla 2.

Las funciones semánticas que pueden ocupar la primera posición argumental se presentan en (16): $:^{23}$

(16) Agente (Agent):

la entidad que controla una Acción

Posicionador (Positioner): la entidad que controla una Posición.

Fuerza (Force): la entidad no controladora que instiga un Proceso

Procesado (Processed): $\quad$ la entidad que sufre un Proceso.

Cero (Zero): la entidad principalmente involucrada en un Estado (17):

Las funciones Procesado y Cero tienen una versión experiencial, como ilustramos en

(17) John (ProcExp) got an interesting idea. John (CeroExp) did not know the story.

Dik (1997: 121) propone las siguientes funciones semánticas para a la segunda y tercera posición argumental:

(18) Meta (Goal):

la entidad afectada o efectuada por la operación de algún controlador (Agente o Posicionador) o Fuerza.

Receptor (Recipient): Ubicación (Location):

Dirección (Direction):

Origen (Source):

Referencia (Reference):

la entidad a la que se transfiere algo.

el lugar en el que algo se ubica.

la entidad hacia la que se mueve algo.

la entidad desde la cual se mueve algo.

el segundo o tercer término de una relación con

referencia al cual se establece la relación.

También las funciones Meta y Receptor tienen su correspondiente versión experiencial, como ilustran los ejemplos de Siewierska (1991: 69) en (19):

22 Las funciones semánticas recuerdan a los casos de la Gramática de Fillmore (1968). (Véase la nota 25).

23 En la teoría de la GF se establece una distinción entre funciones semánticas nucleares y funciones semánticas de satélites. Las primeras definen el papel que desempeñan los argumentos en la predicación, mientras que las segundas caracterizan el papel de los participantes (o especificaciones) adicionales a la misma (cfr. García Velasco 2003: 124). 
(19) a. John scared Mary (MetaExp).

b. John apologized to Peter (RecExp)

La relación entre funciones semánticas y sus posiciones argumentales se resume en la Tabla 4, que presenta las combinaciones más frecuentes de funciones semánticas en la predicación nuclear.

$\begin{array}{ccc}\text { A1 } & \text { A2 } & \text { A3 } \\ \text { Agente } & \text { Meta } & \text { Receptor } \\ \text { Posicionador } & & \text { Ubicación } \\ \text { Fuerza } & & \text { Dirección } \\ \text { Procesado } & & \text { Origen } \\ \text { Cero } & & \text { Referencia }\end{array}$

Tabla 5. Funciones semánticas y posiciones argumentales (Dik 1997: 120)

En la GF las funciones semánticas vienen determinadas no sólo por el contenido de la predicación, sino también por la forma en que ese contenido ha sido expresado (cfr. Dik 1997: 123). Sólo las distinciones semánticas que hayan sido gramaticalizadas por las lenguas, y no aquellas atribuibles a nuestro conocimiento del mundo, constituyen funciones semánticas en el sentido técnico (cfr. Siewierska 1991: 63). Así pues, en (20a), John no es el Receptor, aunque reciba el dinero. La predicación lo presenta como la entidad que sufre un Proceso (Dik 1997: 123). Del mismo modo, "the money" no tiene la función semántica de Instrumento en (20b), aunque su valor semántico sea claramente instrumental:

(20) a. John (Proc) received the money (Meta) from Fred (Origen).

b. John (Ag) used the money (Meta) to bribe the policeman.

Por otra parte, en la GF no se identifican las funciones semánticas Meta y Procesado:

(21) a. John (Ag) moved the rock (Meta).

b. The rock (Proc) moved.

Dik (1997: 122) sostiene que, semánticamente, el estatus de "the rock" no es el mismo en ambos casos, porque sólo en (21a) se desencadena la acción en virtud de una operación externa. Por otra parte, la asignación de la función Meta tiene una clara motivación sintáctica, al estar ligada a la asignación de Sujeto y Objeto (cfr. Mackenzie 1981: 307). ${ }^{24}$

Hay que tener en cuenta, para concluir, que, aunque en el modelo de la GF las funciones semánticas se postulan como nociones universales, el propio Dik (1997: 122) señala que

\footnotetext{
24 En formulaciones más recientes se utiliza el término Paciente para ambas realizaciones (cfr. García Velasco y Hengeveld 2002: 115). En opinión de Mackenzie (1981: 307), la motivación de la función semántica Meta en términos de comportamiento sintáctico debilita la autonomía de la asignación de funciones semánticas y sintácticas. También Siewierska (1991: 71) se muestra partidaria de asignar la misma función semántica a la entidad no controladora que experimenta un cambio, independientemente de que ocupe la primera o la segunda posición argumental.
}

Odisea, $n^{\circ} 12$, ISSN 1578-3820, 2011, 331-349 
la lista de funciones nucleares propuesta no es necesariamente la definitiva y manifiesta sus dudas sobre la validez tipológica de la misma: "None of the distinctions made here is definitive, nor is it clear which and how many nuclear functions would suffice to capture the crosslinguistic inventory of semantic functions."

\subsection{Funciones sintácticas}

Dik (1997: 26) aclara que, si bien en la GF se mantiene la denominación tradicional de "funciones sintácticas", las nociones Sujeto y Objeto son reinterpretadas como funciones que aportan su propia contribución a la semántica de la expresión, determinando diferentes "perspectivas" en el estado de cosas designado por la predicación.

La relación entre las posibilidades de asignación de Sujeto y Objeto y las diferentes funciones semánticas postuladas en la GF se representa en la siguiente Jerarquía de Funciones Semánticas (JFS), que ordena estas funciones según su centralidad respecto a la predicación: ${ }^{25}$

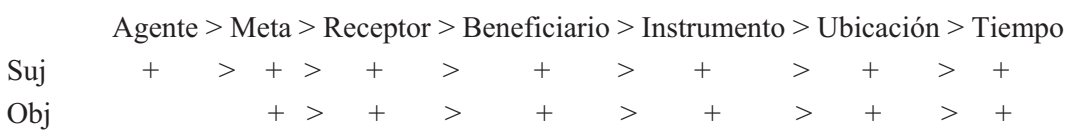

Figura 2. Jerarquía de Funciones Semánticas en la GF (Dik 1997: 266)

En esta jerarquía, que se postula como un universal lingüístico, se toma como rasgo diferenciador el llamado "punto de interrupción" ("cut-off point"), es decir, la última función semántica que puede acceder a la asignación de las funciones sintácticas Sujeto u Objeto en una lengua determinada.

La asignación de Sujeto se define en términos de la oposición entre construcciones activas y pasivas, ejemplificada en (22). En (22a) el estado de cosas se presenta desde la perspectiva del Agente; en (22b) el estado de cosas se presenta desde la perspectiva del constituyente con la función semántica Meta; en (22c) y (22d) el mismo estado de cosas se describe desde la perspectiva del Receptor y el Beneficiario, respectivamente: ${ }^{26}$

(22) a. John (AgSuj) gave the book (MetObj) to Mary (Rec)

b. The book (MetSuj) was given to Mary (Rec) by John (Ag)

c. Mary (RecSuj) was given the book (Met) by John (Ag)

d. Peter (BenSuj) was bought the book (Met) by John (Ag)

Por otra parte, la asignación de la función Objeto se supedita a la existencia del fenómeno denominado "cambio de dativo" ("dative shift"), ejemplificado en (23a) y (23b): ${ }^{27}$

\footnotetext{
25 Es éste uno de los postulados de la GF donde se pone de manifiesto la influencia de la Gramática de Casos de Fillmore (1968). Como indica Dik (1978: 75), Fillmore fue el primero en formular la idea de que las restricciones existentes en la asignación de las funciones gramaticales pueden expresarse en una jerarquía de funciones semánticas. Dik prefiere el término "función semántica" al de "caso", ya que en la GF no se establece una relación especialmente estrecha entre las funciones semánticas y los casos morfológicos.

26 Los ejemplos (22a/b) han sido tomados de (Dik 1997: 64). Los ejemplos (22c/d) proceden de (Dik 1997: 254).

27 Ejemplos tomados de Dik (1997: 65).
} 
(23) a. John (AgSuj) gave the book (MetObj) to Mary (Rec)

b. John (AgSuj) gave Mary (RecObj) the book (Met)

La existencia de este tipo de oposiciones es una condición necesaria para reconocer la aplicabilidad de las funciones Sujeto y Objeto en una lengua. En español, por ejemplo, la asignación de Objeto no es pertinente, ya que, como muestran los ejemplos en (24), el Receptor siempre recibe la misma marca (la preposición a), independientemente de su posición en la oración:

\section{(24) a. Juan le dio el libro a Ana (Rec). \\ b. Juan le dio a Ana (Rec) el libro.}

La función Objeto en inglés no se asigna únicamente a los constituyentes Meta y Receptor. En la teoría de la GF se contempla también la posibilidad, más restringida, de asignación de Objeto a otro constituyente no Meta, el Beneficiario, siempre que éste designe a una entidad animada. La construcción (25b) ejemplifica esta posibilidad: ${ }^{28}$

\section{(25) a. John (AgSuj) bought the book (MetObj) for Peter (Ben) b. John (AgSuj) bought Peter (BenObj) the book (Met)}

El punto de interrupción para la asignación de Objeto en inglés se establece por tanto tras la función semántica Beneficiario en la jerarquía postulada por Dik. También la función Sujeto es aplicable a esta función semántica, como muestra el ejemplo en (22d).

Como observábamos en la Figura 2, en la JFS propuesta por Dik no tenían cabida funciones como Posicionador, Procesado o Cero. Sin embargo, más adelante el autor modifica esta jerarquía y propone la versión de la Figura 3, organizada en torno a las nociones sintáctico-semánticas de primer y segundo argumento $\mathrm{A}^{1} \mathrm{y}^{2}$, y donde se incluyen funciones semánticas adicionales:

$\begin{array}{llll}\mathbf{A}^{\mathbf{1}}> & \mathbf{A}^{\mathbf{2}}> & \text { Rec }> & \text { Ben } \ldots \\ \text { Ag } & \text { Meta } & & \\ \text { Pos } & \text { Rec } & & \\ \text { Fuerza } & \text { Ben } & \\ \text { Proc } & \text { Instr } & \\ \text { Cero } & \text { etc. } & & \end{array}$

Figura 3. Nueva Jerarquía de Funciones Semánticas (Dik 1997: 277).

\footnotetext{
28 Ejemplos tomados de Dik (1997: 264).
} 


\subsection{Aproximaciones críticas}

Entre las aportaciones que se han realizado a lo largo de los últimos años en lo tocante a la organización del léxico y a la asignación de funciones semánticas en la GF destaca, en mi opinión, la aproximación de García Velasco y Hengeveld (2002), que resumiré en esta sección.

García Velasco y Hengeveld (2002: 95-96) hacen dos propuestas interesantes, con amplias repercusiones para la concepción de los EdCs y de las funciones semánticas en el modelo. Por una parte, los autores mencionan la necesidad de introducir un "nivel de representación conceptual pre-lingüístico" en la teoría; por otra, proponen sustituir la noción de marco predicativo de la GF, presentado en (1), por la más general de "marco de predicación" (predication frame), un entorno sintáctico básico para la inserción de lexemas. Sería también necesario introducir un sistema de "engarce" (linking) entre los niveles conceptual y sintáctico, que García Velasco y Hengeveld (2002: 114) ilustran con un sencillo ejemplo que reproduzco en (26):

\section{(26) open [V] \\ $\left[\mathrm{f}_{1}:\left[\operatorname{CAUSE}\left(\mathrm{x}_{1}\right)\right.\right.$ [BECOME open' $\left.\left.\left.\left(\mathrm{x}_{2}\right)\right]\right]\right]$}

En (26) se indica que el lexema open (“abrir") designa una relación (representada por la variable "f") entre dos entidades (representadas por las variables "x"). La presencia de estas variables en la definición "guía el proceso de engarce hacia la selección de un marco de predicación transitivo" (García Velasco y Hengeveld 2002: 114). ${ }^{29}$

El marco de predicación para el lexema open recibiría la siguiente representación en su uso transitivo, en oraciones como Sheila opened the door (García Velasco y Hengeveld 2002: 115$):{ }^{30}$

$$
\text { (27) }\left(\mathrm{T}^{1}:\left(\mathrm{f}_{1} \text { : open }[\mathrm{V}]\left(\mathrm{f}_{1}\right)\right)\left(\mathrm{T}_{1}\right)\right)\left(\mathrm{R}_{1}:\left(\mathrm{x}_{1}\right)_{\mathrm{Ag}}\left(\mathrm{R}_{1}\right)\right)\left(\mathrm{R}_{2}\left(\mathrm{x}_{2}\right)_{\mathrm{Pat}}\left(\mathrm{R}_{2}\right)\right)
$$

En esta propuesta, el rol de cada uno de los participantes en la predicación se puede obtener a partir de la definición de significado abstracto del lexema, y se permite que un mismo predicado pueda escoger marcos de predicación alternativos, si tiene más de una definición de significado.

El propio García Velasco (2003: 129) formula como sigue las consecuencias que tendría la introducción de un componente conceptual pre-lingüístico para la noción de función semántica en el modelo:

En lo que se refiere a las Funciones Semánticas, la introducción de un sistema de representación conceptual y su aplicación al análisis del significado léxico tiene como consecuencia que dejen de ser consideradas primitivos de la teoría semántica. Asimismo,

\footnotetext{
29 Véase también García Velasco (2003: 117).

30 En (27) se utiliza el formalismo empleado en la Gramática Funcional del Discurso, donde las funciones de referencia y adscripción se indican mediante las variables R y T, respectivamente. En su uso intransitivo, el lexema open recibiría otra representación.
} 
presenta la ventaja de solucionar uno de los problemas endémicos que se plantea con el uso de estas relaciones: la aparente imposibilidad de evitar la proliferación de su número.

Por otra parte, esta propuesta tiene también implicaciones en lo referente a la teoría de los EdCs, que "formarían parte de un modo natural del nivel de representación conceptual, ya que resultan de abstracciones cognitivas de los distintos tipos de eventos a los que un hablante puede hacer referencia" (García Velasco 2003: 129).

\section{COMENTARIOS FINALES}

En este trabajo he pretendido ofrecer una revisión crítica del nivel de representación semántica donde se conforma el primero de los niveles jerárquicos del enunciado en la teoría de la GF, la predicación nuclear. Especialmente interesante, resultan en mi opinión, las aportaciones de García Velasco y Hengeveld en su artículo de 2002, donde se plantea de nuevo el debate sobre la relación entre el componente cognitivo y el gramatical en el seno de la GF. ${ }^{31}$

Cabe mencionar que en la Gramática Funcional del Discurso (GFD; Hengeveld y Mackenzie 2008), las funciones semánticas y sintácticas no son tan centrales como lo eran en el modelo anterior y, como afirma Salazar García (2009: 390), pasan a desempeñar un "papel sensiblemente más limitado que se relaciona sobre todo con el alineamiento sintagmático (alignment) de los constituyentes, en su tránsito desde los niveles pragmático y semántico al morfosintáctico”. En la GFD, las funciones semánticas no se postulan como funciones con validez universal, ya que la teoría no asume a priori que las representaciones semánticas subyacentes sean idénticas para todas las lenguas. En palabras de Hengeveld y Mackenzie (2008: 194):

FDG [Functional Discourse Grammar] does not assume a priori that underlying semantic representations are identical across languages, but that they have to be determined for each language individually, based on the grammatically relevant distinctions that are made within that language.

Las funciones semánticas son definidas ahora como simples "reflejos gramaticales" de la conciencia cognitiva del hablante respecto a las diferentes funciones que los participantes pueden desempeñar en un EdC (Hengeveld and Mackenzie 2008: 195).

Por otra parte, en este marco teórico las funciones sintácticas (o gramaticales), que ya no se definen como "funciones de perspectiva" (cf. sección 3.1), ${ }^{32}$ tampoco se presentan como funciones universales ni como primitivos en la teoría. En la GFD las funciones sintácticas

\footnotetext{
31 En opinión de García Velasco (2003: 277), la relación entre ambos componentes ha de ser gradual, y la propuesta de García Velasco y Hengeveld (2002) permitiría en efecto una transición natural de uno a otro.

32 La diferencia de enfoque en el tratamiento de las funciones sintácticas entre los modelos de la GF y la GFD, en éste último supeditadas a factores semánticos y pragmáticos, es claramente formulada por Hengeveld (2005: 358) en estos términos: "[In FDG] Syntactic functions are thus no longer considered to be perspectivizing in nature, as they are in FG. Rather, they are matched to pragmatic and semantic units as part of the encoding operation. The pivotal nature of syntactic functions can thus be attributed to the semantic and pragmatic factors that trigger their occurrence."
} 
se consideran como nociones relevantes sólo cuando se produce una neutralización de las distinciones semánticas y pragmáticas a efectos morfosintácticos: 33 "Syntactic functions are relevant only in those cases in which the formal properties of linguistic units cannot be reduced to the pragmatic and the semantic categories and functions underlying them" (Hengeveld y Mackenzie 2008: 316).

En mi opinión, un modelo de orientación descendente como la GFD, centrado en la pragmática y no en las unidades léxicas aisladas (Anstey 2004: 45; García Velasco 2003: 264), permite una concepción mucho más flexible de los EdCs y de la asignación de funciones semánticas y sintácticas, que no está tan severamente restringida como en el modelo de la GF, su precedesor.

\section{REFERENCIAS BIBLIOGRÁFICAS}

Anstey, M. 2004. "Functional Grammar from its inception". A New Architecture for Functional Grammar. Eds. J. L. Mackenzie y M. A. Gómez-GonzÁlez. Berlin/N. York: Mouton de Gruyter. 23-71.

Butler, C. S. 2003. Structure and Function. A Guide to Three Major StructuralFunctional Theories. Part I: Approaches to the Simplex Clause. Amsterdam: John Benjamins.

Comrie, B. 1976. Aspect. Cambridge: Cambridge University Press.

De Groot, C. 1983. "Typology of States of Affairs". Linguistics in the Netherlands 1983. Eds. H. Bennis y W. U. S. van Lessen Kloeke. Dordrecht: Foris. 73-81.

---. 1985. "Predicates and terms". Predicates and Terms in Functional Grammar. Eds. A. M. Bolkenstein, C. De Groot y J. L. Mackenzie. Dordrecht : Foris. 71-84.

Depraetere, I. 1995. "On the necessity of distinguishing between (un)boundedness and (a)telicity". Linguistics and Philosophy 18: 1-19.

Dik, S. C. 1978. Functional Grammar. Amsterdam: North Holland.

---. 1981/1978. Gramática funcional. Versión española de L. Martín Mingorance y F. Serrano Valverde. Madrid: SGEL.

---. 1989. The Theory of Functional Grammar. Dordrecht: Foris.

---. 1997. The Theory of Functional Grammar. Part 1: The Structure of the Clause. Ed. K. Hengeveld. Berlin/N. York: Mouton de Gruyter.

Dowty, D. R. 1979. Word Meaning and Montague Grammar. Dordrecht: Reidel.

Fillmore, C. J. 1968. “The case for case”. Eds. E. BACH y R. T. Harms. Universals in Linguistic Theory. N. York: Holt, Rinehart and Winston. 1-88.

\footnotetext{
33 Las categorías Actor, Undergoer y Locative sí se definen en cambio como nociones con validez universal en el modelo. Hengeveld and Mackenzie (2008: 199) las presentan como "general indications of (groups of) semantic functions which we hypothezise to be of universal relevance".
} 
García Velasco, D. 2003. Funcionalismo y Lingüística: La Gramática Funcional de S.C. Dik. Oviedo: Servicio de Publicaciones de la Universidad.

---. y K. Hengeveld. 2002. "Do we need predicate frames?" New Perspectives on Argument Structure. Eds. R. Mairal y M. J. Pérez Quintero. Berlin/N. York: Mouton de Gruyter. 95-123.

Goossens, L. 1990. "Mental processes and relational verbs and the typology of states of affairs in FG". Working with Functional Grammar: Descriptive and Computational Applications. Eds. M. Hannay y E. Vester. Dordrecht: Foris. 167-186.

Guerrero Medina, P. 1998. "A prototype approach to transitivity: its implications for the FG typology of SoAs". The Structure of the Lexicon in Functional Grammar. Eds. H. Olbertz, K. Hengeveld y J. SÁnchez. Amsterdam/Philadelphia: John Benjamins. 215-232.

---. 2001. "Reconsidering aspectuality: interrelations between grammatical and lexical aspect". Working Papers in Functional Grammar 75. Disponible en: http://home. hum.uva.nl/fg/publications_papers.html

Halliday, M. A. K. 1985. An Introduction to Functional Grammar. London: Edward Arnold.

Hengeveld, K. 1989. "Layers and operators in Functional Grammar". Journal of Linguistics 25: 127-157.

---. 2005. "Dynamic expression in Functional Discourse Grammar". Morphosyntactic Expression in Functional Grammar. Eds. C. DE Groot y K. Hengeveld. Berlin/N. York: Mouton de Gruyer. 53-86.

---. y J. L.MACKenZIE. 2008. Functional Discourse Grammar: A Typologically-based Theory of Language Structure. Oxford: Oxford University Press.

Mackenzie, J. L. 1981. "Functions and cases". Perspectives on Functional Grammmar. Eds. T. Hoekstra, H. van der Hulst y M. Moorgat. Dordrecht: Foris. 299-318.

Quirk, R., S. Greenbaum, G. Leech y J. Svartvik. 1985. A Comprehensive Grammar of the English language. Londres: Longman

Rijksbaron, A. 1989. Aristotle, Verb Meaning and Functional Grammar. Towards a New Typology of States of Affairs. Amsterdam: J.C. Gieben

Salazar García, V. 2009. "Reseña de Hengeveld, K. y J. L.Mackenzie, 2008. Functional Discourse Grammar: A Typologically-based Theory of Language Structure. Oxford University Press". E.L.U.A. (Estudios de Lingüistica Universidad de Alicante) 23: 387-392.

SiEwIERSKA, A. 1991. Functional Grammar. London: Routledge.

Sото, G. 2008. "Sobre el llamado futuro de probabilidad. Algunas condiciones del valor modal de -ré". Boletín de Filología. Tomo XLIII: 193-206. 
Van Valin, R. D. y R. J. LaPolla 1997. Syntax: Structure, Meaning and Function. Cambridge: Cambridge University Press.

Vendler, Z. 1967. Linguistics in Philosophy. Ithaca, NY: Cornell University Press.

Vester, E. 1983. Instrument and Manner Expressions in Latin. Assen: Van Gorcum. 